\title{
Type 1 (insulin-dependent) diabetes in Tasmania: prevalence and apparent regional differences
}

\author{
H. King ${ }^{1,3}$, J. Dixon ${ }^{1}$, G. Senator ${ }^{2}$, M. Schooneveldt ${ }^{3}$ and P.Zimmet ${ }^{3}$ \\ ${ }^{1}$ Department of Community Health, University of Tasmania, ${ }^{2}$ Department of Endocrinology, Royal Hobart Hospitall, Hobart, and \\ ${ }^{3}$ Lions International Diabetes Institute, Royal Southern Memorial Hospital, Melbourne, Australia
}

\begin{abstract}
Summary. The results of a cross-sectional study of Type 1 (insulin-dependent) diabetes in the total population of Tasmania are described. Tasmanians, predominantly of British origin, live in a temperate island situated to the south-east of mainland Australia. For males and females respectively, prevalence in 1984 was $1.1 \pm 0.1$ and $0.9 \pm 0.1$ per 1,000 at all ages, $0.6 \pm 0.2$ and $0.5 \pm 0.2$ per 1,000 in subjects aged $0-14$ years, rising to $1.2 \pm 0.2$ and $1.1 \pm 0.2$ per 1,000 in those aged $0-29$ years. Prevalence in the $0-19$ year age range was $0.8 \pm 0.2$ per 1,000 in both sexes. Prevalence fell in both sexes from the third decade of life. A statistically significant excess
\end{abstract}

in prevalence was found in the urban, as compared with the rural, sector of the community. The urban relative risk was greatest in subjects aged 10-19 years. According to reported month of onset (commencement of insulin treatment) there was a suggestion of seasonal trend in the rural, but not in the urban subjects. Longitudinal studies of Type 1 diabetes in Tasmania are now required if these findings are to be confirmed, and their possible aetiological implications explored.

Key words: Diabetes mellitus, insulin-dependent, epidemiology, seasons, rural population, urban population.
The Tasmanian Insulin-treated Diabetes Register was established in 1984. It aims to describe the epidemiology of insulin-treated diabetes in a well-defined population of moderate size and to provide a sound framework for longitudinal population-based research into the disease.

The first phase of the project was the recruitment of subjects of all ages who were resident in Tasmania and treated with insulin on the chosen prevalence date, 1 May 1984. The present report describes the results of this cross-sectional prevalence survey, with respect to those subjects considered to have Type 1 (insulin-dependent) diabetes.

\section{Subjects and methods}

\section{Background}

Tasmania is an island with a temperate climate and a land area of 67,800 square $\mathrm{km}$. Lying between latitudes $40-43^{\circ}$ south of the equator, it is the smallest and most south-easterly state of Australia. Tasmania has a population of 442,000 , almost all of whom are of British ancestry.

With discrete boundaries, a stable population, centralised health services and well defined rural and urban sectors, the island provides excellent opportunities for the epidemiological study of many chron- ic diseases, including diabetes mellitus. The ancestry of the Tasmanian population also favours comparisons with those of Europe and North America, as well as other Caucasian populations in Australasia. Such comparisons are of considerable value, not only for defining the descriptive epidemiology of insulin-dependent diabetes around the world, but also in the search for, and evaluation of, putative risk factors for the disease [1].

\section{Subjects}

Eligible subjects throughout the state were recruited through specialist clinics, hospital records, general practices, pharmacies and media publicity over a two-year period, 1984-1986. Procedural details have been published elsewhere [2].

Entry criteria for the register were: (1) a physician diagnosis of diabetes, and (2) residence in Tasmania and treatment with insulin on the prevalence date. In the absence of a universally accepted epidemiological definition of Type 1 diabetes, additional criteria for eligibility for the present study were: (1) age at onset $<30$ years, and (2) insulin treatment known to have commenced at, or within 1 month of, diagnosis.

Whilst it was not expected that these criteria would be either totally sensitive or totally specific for Type 1 diabetes, it was felt that they offered a reasonable compromise between these two ideals; a fairly high degree of specificity in addition to recruitment of a larger cohort than would have been possible using the lower age limits imposed by some other registers of this disease.

The target population of eligible subjects was enumerated by staff of the Tasmanian Division, Commonwealth Department of Health, on the basis of insulin prescriptions which were tendered for financial rebate during a six-month period, May-November 1984, to 
Table 1. Prevalence of Type 1 (insulin-dependent) diabetes in Tasmania, 1984

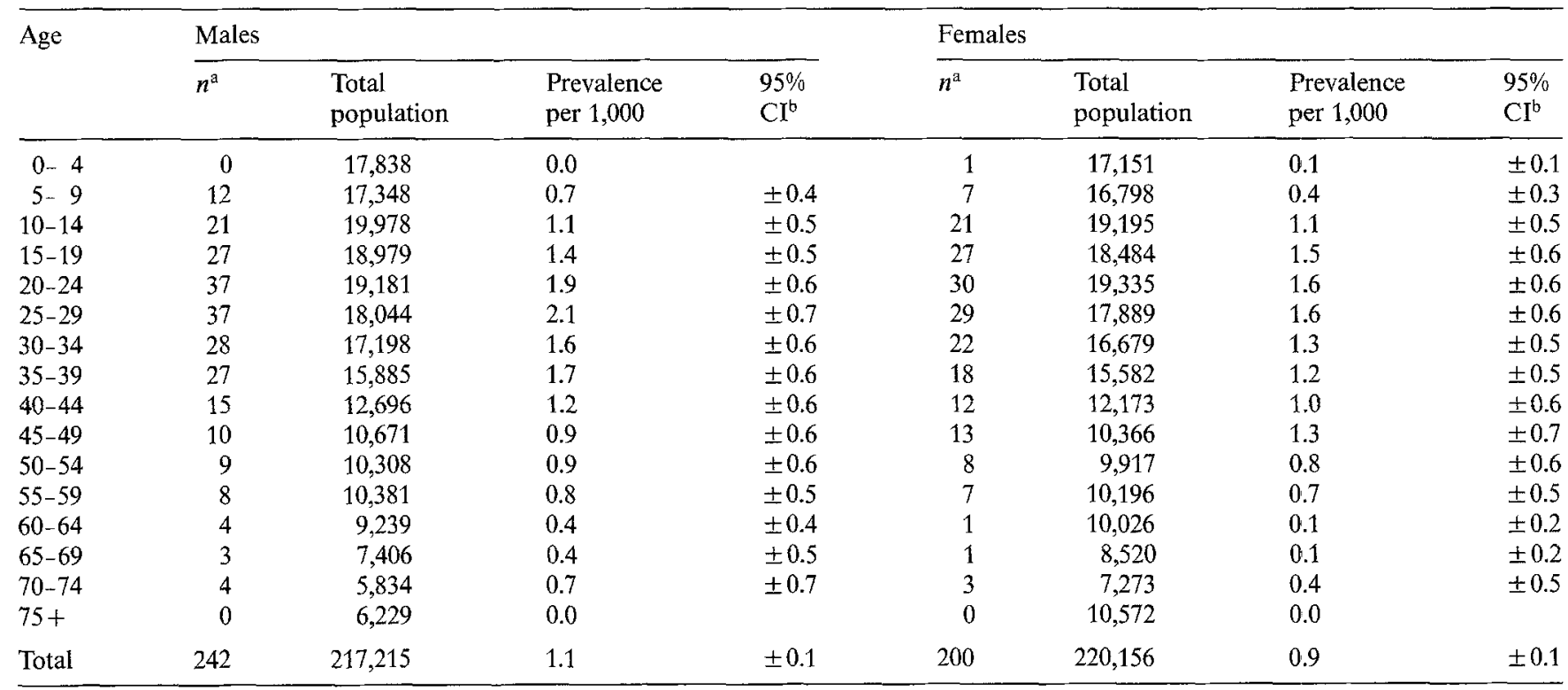

${ }^{a}$ Number of diabetic subjects, ${ }^{b}$ Confidence interval (CI)

which were added names of subjects receiving insulin during the same period through hospital clinics, the only other source of insulin in Tasmania.

The total population of insulin-treated residents as of 1 May 1984 was estimated by these means to number 1,318 subjects. Of these, 1,233 registered in the study, a response rate of $94 \%$. Approximately one-third (442) of these insulin-treated subjects fulfilled the present study criteria for Type 1 diabetes.

\section{Missing data}

For one eligible subject, day and month of birth were not known, but this did not influence the numerator for the 5-year prevalence estimates (the subject was born in 1961). For 102 subjects, month of diagnosis could not be recalled, and these were not included in the assessment of seasonal trends. For the purpose of calculating age at onset, they were assigned a mid-year date of onset ( 1 July).

\section{Validation}

For an assessment of the accuracy of the data collection, a random $10 \%$ of all registered subjects were re-interviewed, the interviewer being unaware of the original responses. Concordance of response to the questions relating to sex, date of birth, date of diagnosis, date of onset of insulin treatment and place of residence at diagnosis for the 43 of the 442 subjects eligible for the present study, who were included in the validation exercise, was as follows: subject's sex was recorded similarly in every case; two subjects gave discrepant dates of birth; one of these, and two additional subjects gave discrepant information regarding place of residence; in only two cases were eligibility criteria discrepant.

In view of necessary reliance on human memory in this retrospective study, the results were judged to indicate a satisfactory standard of recall on the part of interviewees, and of recording on the part of interviewers.

\section{Population denominators}

For the estimation of rates for Tasmania as a whole, estimates for 5 -year age groups for the June 1984 quarter were obtained from figures published by the Australian Bureau of Statistics [3]. For regional comparisons, the latest age-sex-specific figures available for each municipality were those of the 1981 census [4] and these were used for age-standardisation against the estimates for the total population in June 1984.

\section{Statistical analysis}

Basic descriptive statistics were generated using the Statistical Package for the Social Sciences [5]. Confidence intervals were calculated by the method of Armitage [6]. Age standardisation was by the indirect method, the total population of Tasmania in June 1984 being taken as the standard. Relative risk for rural-urban comparisons was calculated by the Mantel extension of the Mantel-Haenszel procedure [7]. Seasonal trend was assessed by the method of Roger [8].

\section{Results}

\section{Prevalence}

Age- and sex-specific prevalence rates per 1,000 persons, and their $95 \%$ confidence intervals, are shown in Table 1. Only one (female) subject was aged less than 5 years and none was over 75 years of age. There was a slight excess in prevalence in males. Prevalence rose with age to the third decade of life, after which it fell progressively in both sexes.

In order to enhance comparability with other reports, estimates were also calculated in broader age ranges. Prevalence was $0.6 \pm 0.2$ and $0.5 \pm 0.2$ in males and females, respectively, in subjects aged $0-14$ years and $0.8 \pm 0.2$ per 1,000 in both sexes aged $0-19$ years. In subjects aged $0-29$ years it rose to $1.2 \pm 0.2$ and $1.1 \pm 0.2$ per 1,000 in males and females respectively.

\section{Age at onset}

The age at which cases most frequently reported onset of insulin therapy was 13 years for females and 
Table 2. Comparisons of the prevalence of Type 1 (insulin-dependent) diabetes in various age ranges in the rural and urban sectors in Tasmania, 1984

\begin{tabular}{|c|c|c|c|c|c|c|}
\hline \multirow[t]{2}{*}{ Age group } & \multicolumn{2}{|c|}{ Rural } & \multicolumn{2}{|c|}{ Urban } & \multirow[t]{2}{*}{$\mathrm{RR}^{\mathrm{a}}$} & \multirow[t]{2}{*}{$p$} \\
\hline & $n^{\mathrm{b}}$ & Prev $/ 1,000$ & $n^{\mathrm{b}}$ & Prev $/ 1,000$ & & \\
\hline $0-9$ & 3 & 0.42 & 16 & 0.61 & 1.4 & NS \\
\hline $10-19$ & 6 & 0.98 & 80 & 2.63 & 2.7 & $<0.05$ \\
\hline $20-29$ & 18 & 2.72 & 107 & 3.94 & 1.5 & NS \\
\hline $30+$ & 23 & 1.40 & 130 & 1.68 & 1.2 & NS \\
\hline $0-29^{\mathrm{c}}$ & 27 & 1.40 & 203 & 2.42 & 1.7 & $<0.01$ \\
\hline All ages ${ }^{c}$ & 50 & 1.32 & 333 & 1.96 & 1.5 & $<0.05$ \\
\hline
\end{tabular}

${ }^{a}$ Relative risk (RR) for urban subjects, calculated by the Mantel extension of the Mantel-Haenszel procedure [7]. ${ }^{\mathrm{b}}$ Number of diabetic subjects (a total of 59 subjects were not resident in Tasmania at the time of diagnosis). ${ }^{c}$ Age-standardised prevalence rates are shown in the broad age ranges. NS, not significant

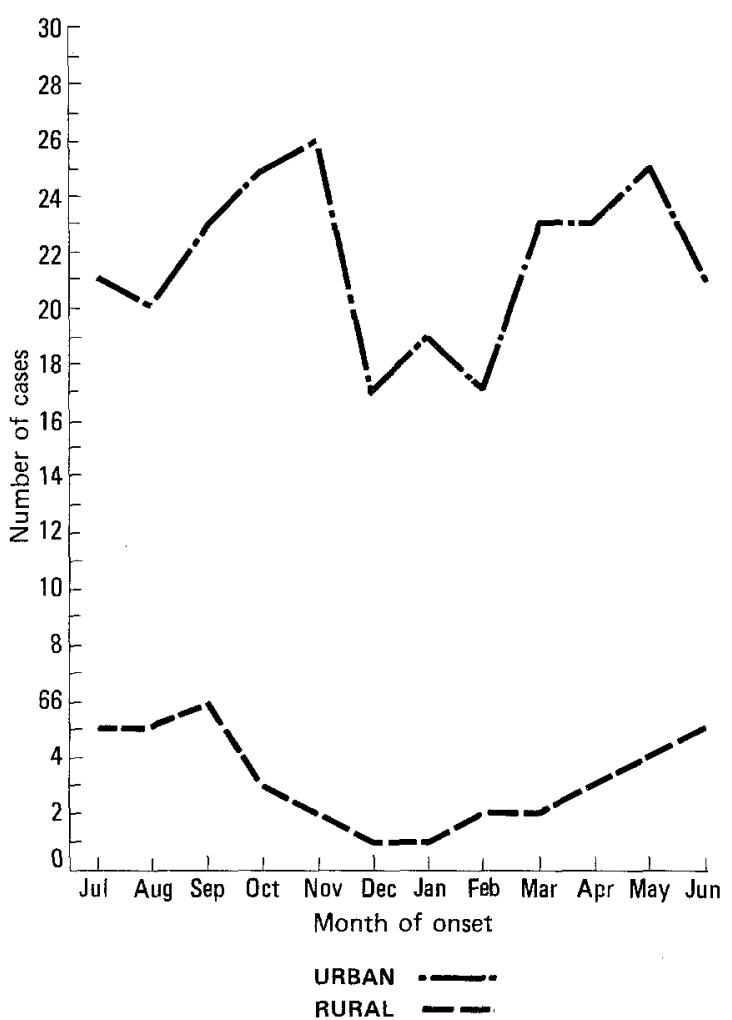

Fig. 1. Seasonality of onset (commencement of insulin treatment) of Type 1 (insulin-dependent) diabetes in prevalent subjects with onset $<30$ years in rural and urban sectors in Tasmania, 1984. Threemonth moving averages

16 years for males. A number of cases reported onset after the age of 20 years. These findings, which should be treated with some caution in view of their retrospectivity, support true incidence data from other populations.

\section{Regionality}

For the purpose of regional comparisons in population studies in Tasmania, six demographically pertinent re- gions, based upon aggregations of municipalities (Local Government Areas) have recently been recommended [9]. Three of these contain urban foci ( $>$ 30,000 persons), whilst the other three are uniformly rural. The definition of these regions is the result of extensive demographic investigation [10]. For the purpose of the present study, the three urban and three rural regions were each combined, to give two contrasting populations.

Prevalence of Type 1 diabetes in these rural and urban sectors of the community, with subjects categorised according to place of residence at the time of diagnosis (in order to exclude possible bias due to selective migration of diabetic subjects to an urban environment for greater proximity to health and other services) are shown in various age ranges in Table 2 along with the relative risks for urban subjects.

In each age group, there was an excess risk for the urban subjects. The relative risk for urban subjects was highest $(R R=2.7)$ in those aged $10-19$ years, the only 10 -year age group in which it was statistically significant. However, when examining the data by broader age categories, improving group numbers and the power of statistical comparisons, urban risk proved highly significant $(p<0.01)$ to age 30 years.

\section{Seasonality}

For those subjects recalling month of onset (commencement of insulin treatment) seasonal trends were ascertained. Although there was a discernable decline in the number of cases occurring in the December-February quarter, which corresponds to the austral summer, this was, in fact, due to a very low number of cases in a single month, January.

Seasonal trends were also examined in rural and urban populations separately. Of rural subjects, $70 \%$ reported commencing insulin treatment in the second and third quarters (April-September) as compared with 51\% during the same period in the urban subjects. Whereas the urban subjects demonstrated the seasonal pattern shown by the total population, the rural subjects exhibited a more symmetrical trend (Fig.1). Roger's test confirmed a significant $(p<0.1)$ seasonal trend in the rural group, but not in the urban group or the total sample.

\section{Discussion}

Few detailed reports have been published on the epidemiology of Type 1 diabetes in populations of European ancestry presently living in the Southern Hemisphere. Such studies are potentially highly informative, in view of the marked heterogeneity in incidence and prevalence of the disease in different populations in the Northern Hemisphere [1]. 
The estimated prevalence of Type 1 diabetes in Tasmania in 1984 in the age range $0-19$ years $(0.8$ per 1,000 ) is very close to the figure of 0.7 per 1,000 reported in the same age range in the Illawarra area, New South Wales for 1985 [11]. Both estimates are lower than those recently reported for a population in a similar latitude in South Island, New Zealand (1.1 and 1.0 per 1,000 for males and females respectively [12]).

Glatthaar et al. [13] have reported a prevalence of diabetes at all ages in Busselton, Western Australia of $2-4 \%$ and these investigators estimated that $14 \%$ of such subjects were insulin-dependent, suggesting an all-ages prevalence of Type 1 diabetes of 2.8-5.6 per 1,000 . This is considerably higher than the corresponding Tasmanian figure. However, when making such comparisons, it should be noted that prevalence estimates may be markedly influenced by eligibility criteria and other aspects of study design, emphasising the need for their careful standardisation [1].

Compared with estimates from Europe, the prevalence of Type 1 diabetes in Tasmania appears to be intermediate between that of Switzerland [14] and the United Kingdom [15]. Comparing the Tasmanian data with the findings of a 1973 study in Funen County, Denmark [16] which used similiar methodology in a demographically comparable population [17] pr 'lence was almost two fold higher in those with $r$ t under 30 years in Denmark. Both studies show $\sin _{x_{\omega}} d r$ trends with age. Whilst the fall in prevalence from the third decade may be due to natural attrition, cohort effects should not be discounted, in view of recent reports of a secular increase in incidence in several populations.

The apparent excess prevalence of Type 1 diabetes in the urban sector in Tasmania accords with a similar, though non-significant, observation recently reported from Wisconsin, USA [18] but contradicts a rural excess in risk reported from Scotland [19]. An excess in incidence of Type 1 diabetes in a large population focus $(>100,000$ persons), over all other areas of the region, has also recently been described in Midwest Poland [20].

Since this urban excess could provide a focus for prospective investigation of Type 1 diabetes in Tasmania, biases which might have led to the finding should be considered carefully.

The urban excess could not be accounted for by selective emigration of rural diabetic patients wishing for greater access to medical services, since residence was preferentially defined as that at the time of diagnosis, rather than that at the time of the study, in order to obviate this potential bias.

Rural depopulation has been a feature of recent Tasmanian demography [10]. However, non-selective migration towards urban areas (i.e. of both diabetic and non-diabetic subjects in equal proportion) would be expected to mask, rather than to accentuate, the rural deficit. This is because (classifying subjects accord- ing to residence at diagnosis) diabetic migrants remain in the rural numerator whilst non-diabetic migrants are lost from the rural denominator. For the urban population, migrants only augment the denominator.

Whilst our regional classification grouped as urban all subjects in areas relating to the major urban foci (whether or not they actually resided in the towns) this simple demographic distinction serves as a convenient dichotomy with respect to a number of socio-economic, occupational and ancestral genetic influences in the Tasmanian population [9]. Any misclassification with respect to urbanity could also be expected to reduce the true rural-urban differences.

The possibility of higher mortality from Type 1 diabetes in the rural sector, though potentially an important consideration, seems unlikely, since specialist endocrinological coverage is complete in this relatively small island.

Selective under-ascertainment of rural diabetic subjects is a factor which cannot be totally excluded, though it is also unlikely, given the high overall response (94\%) and good communications within the rural Tasmanian community.

The suggestion of a possible difference in seasonal trends of onset between the rural and urban sectors (which might be explained by the greater ubiquity of infectious agents or other precipitants in urban surroundings) is intriguing. However, whilst supporting recent data from the Wisconsin study [18], the findings with respect to seasonality should be considered entirely preliminary and in need of confirmation by true incidence data. Potential pitfalls in their interpretation might include a systematic bias in survival or migration pressure, consequent upon season of onset, and the fact that the data were collapsed over a number of different years. The very small number of cases reported for the month of January in the urban group also raises the possibility of ascertainment bias.

Whilst the date of commencement of insulin treatment might seem an unsatisfactory approximation to onset in some respects, in this apparently latent disease, it has the advantage of precision. Seasonality in the terminal phase of the process of pancreatic destruction, culminating in the need for insulin therapy, is in itself of consequence in the search for acute, and possibly preventable, precipitants.

Taken as a whole, the results of this study suggest that the epidemiology of Type 1 diabetes in Tasmania is similar to that in comparable populations in Europe. It is hoped that the Tasmanian Diabetes Register may now serve as the basis for prospective research.

Acknowledgements. The authors would like to thank Dr. A. Green for assistance in designing the Tasmanian Diabetes Register; the Tasmanian Division, Commonwealth Department of Health for assistance in determining the target population; and Dr. M. Rewers for testing the data for seasonality. Research funds were provided by the WHO Collaborating Centre for the Epidemiology of Diabetes Mellitus, Melbourne and the Diabetes Youth Foundation of Australia. Facili- 
ties were provided by the Department of Community Health, University of Tasmania. Srs. A. Harris, C. Hurst, B. Kelly and J. Williams assisted with data collection.

\section{References}

1. LaPorte RE, Tajima N, Åkerblom HK, Berlin N, Brosseau J, Christy M, Drash AL, Fishbein H, Green A, Hamman R, Harris M, King H, Laron Z, Neil A (1985) Geographic differences in the risk of insulin-dependent diabetes mellitus: the importance of registries. Diabetes Care 8 [Suppl 1]: 101-107

2. King H, Senator G, Zimmet P, Harris A (1986) The Tasmanian Insulin-treated Diabetes Register: inception and progress in the first 12 months. Med J Aust 144: 414 416

3. Australian Bureau of Statistics (1984) Australian demographic statistics. September and December quarters, 1984, Cat No 3101.0. ABS, Canberra, p 11

4. Australian Bureau of Statistics (1983) Age distribution of the estimated resident population in local government areas, Tasmania, 30 June 1981, Cat No 3203.6. ABS, Hobart

5. Nie NH, Hull CH, Jenkins JG, Steinbrenner K, Bent DH (1975) Statistical package for the Social Sciences, 2nd edn. McGrawHill, New York

6. Armitage P (1971) Statistical methods in medical research. Blackwell, Oxford, pp 113-115

7. Mantel N (1963) Chi-square tests with one degree of freedom: extensions of the Mantel-Haenszel Procedure. J Am Stat Assoc 58: $690-700$

8. Roger JH (1977) A significance test for cyclic trends in incidence data. Biometrika 64: 152-155

9. King H, Mitchell RJ, Kosten M (1987) Geographical boundaries for regional comparisons in population studies in Tasmania. In: King $\mathrm{H}$ (ed) Epidemiology in Tasmania. Brolga, Canberra, pp 267-272

10. Mitchell RJ, Kosten M, Williams J (1987) Historical demography and genetic structure of Tasmania. In: King H (ed) Epidemiology in Tasmania. Brolga, Canberra, pp 1-21

11. Moses RG, Matthews JA (1986) Prevalence of diabetes mellitus in Australia. The establishment of a register of diabetic children aged 0 to 19 years in the Illawarra area. Med J Aust 144: 630-632

12. Mason DR, Scott RS, Darlow BA (1987) Epidemiology of insulin-dependent diabetes mellitus in Canterbury, New Zealand. Diabetes Res Clin Pract 3: 21-29

13. Glatthaar C, Welborn TA, Stenhouse NS, Garcia-Webb P (1985) Diabetes and impaired glucose tolerance: a prevalence estimate based on the Busselton 1981 survey. Med J Aust 2: 778-783

14. Teuscher A, Zuppinger K, Luscher R, Moser H (1975) Häufigkeit des jugendlichen Diabetes mellitus im Kanton Bern (Schweiz). Schweiz Med Wochenschr 105: 1218-1233

15. Stewart-Brown S, Haslum M, Butler N (1983) Evidence for increasing prevalence of diabetes mellitus in childhood. Br Med J 286: 1855-1857

16. Green A, Hauge M, Holm NV, Rasch LL (1981) Epidemiological studies of diabetes mellitus in Denmark II. A prevalence study based in insulin prescriptions. Diabetologia 20:468-470

17. Green A (1987) Demographic characteristics of the present population of Tasmania. In: King $\mathrm{H}$ (ed) Epidemiology in Tasmania. Brolga, Canberra, pp 23-34

18. Allen C, Palta M, D'Alessio DJD (1986) Incidence and differences in urban-rural seasonal variation in Type 1 (insulin-dependent) diabetes in Wisconsin. Diabetologia 29: 629-633

19. Waugh LNR (1986) Insulin-dependent diabetes in a Scottish region: incidence and urban/rural differences. J Epidemiol Community Health 40: 240-243

20. Rewers M, LaPorte RE, Walezak M, Dmochowski K, Bogaczynska E (1987) Apparent epidemic of insulin-dependent diabetes mellitus in Midwestern Poland. Diabetes 36: 106-113

Received: 21 September 1987

and in revised form: 29 December 1987

\section{Dr. H. King}

Division of Noncommunicable Diseases/OND

World Health Organization

CH-1211 Geneva 27

Switzerland 